\title{
Study on the Enrolment System of Higher Education in the U.S.A and Its Enlightenments to China
}

\author{
Hui Cheng ${ }^{1}$, Ming-Chen $\mathrm{Wei}^{2}$ \\ ${ }^{1)}$ Department of Foreign Language, Weifang College, Weifang, Shandong, China \\ ${ }^{2)}$ Department of Teachers' Education, Weifang College, Weifang, Shandong, China
}

\begin{abstract}
The paper carries out study on the enrolment system of higher education in the U.S.A and draws enlightenments to China from three aspects: test contents, format and evaluation. On the whole, the paper is made up of two parts. Systematically, part one makes comparative study on the college entrance examination between them, which is mainly concentrated on its background and feature. Then details are given on the test contents, format and scoring of the entrance examination. Part two tells what we can learn from SAT model is stated, that is to set up dynamic, flexible and plural types of evaluation mechanism.
\end{abstract}

Keywords—enrolment system, comparison, enlightenments

\section{美国高校入学考试对我国高考的启示}

\author{
程 辉 $^{1}$ 魏晨明 $^{2}$ \\ 1) 潍坊学院外国语学院, 潍坊, 山东, 中国 \\ ${ }^{2)}$ 潍坊学院教师教育学院, 潍坊, 山东, 中国
}

摘 要 本文通过对美国高校入学考试制度展开研究, 并从考试形式、考试内容、考试评价三个方面思考了其对我国高考的启示。 全文分为两个部分, 第一部分首先是进行中美高校入学考试的对比与分析, 包括背景与特点; 考试形式、内容和评价的对比; 第二部 分是探讨了美国高校入学评价体系对我国高考改革的启发，即建立动态、灵活、多元化的考试评价体系的建立与展望。

关键词 入学考试、对比、愿景

1. 中美高校入学考试的对比

本研究将选取中国与美国高校入学测试对比研究为重 点。

\section{1 背景与特点}

中国高校入学考试(高考)的背景包括社会需要、国家发 展等, 其测试内容和方式也经历了一个由随意性逐步走向 标准化、科学化、规范化的过程; SAT和 ACT, 中文名称 为学术能力评估测试, 简称: 美国高考。由美国大学委员 会主办, 留学生除了提供托福或雅思等语言成绩外, $90 \%$ 以上的美国顶尖名校会要求参考学生的 ACT 或 SAT 成绩,
而且 ACT 或 SAT 成绩的高低已成为决定学生能读哪一所美 国大学的主要因素之一。

(1)背景: 科举考试有一千三百年的历史, 我国现代考试 制度受科举影响很深。在中国知识分子中形成了教条主义、 形式主义的学习风气。美国的高校入学考试, 既学习了欧 洲的理念, 同时又结合自己国内的现状与实际将美国的高 等教育大力得推进、发展。

(2)特点: 美国文化多样化发展与中国统一儒家文化的 差别, 不同的文化使得美国考试多样性，而中国高考是统 一、标准化的。美国“个人取向”和中国人“社会取向”的文化 价值观念的差别, 不同的价值观使得美国考试重视的是个 体自我发展过程的纵向比较，而中国高考是注重外在表现，

程辉 (1973), 女, 山东淮坊人

地址: 山东潍坊东风东街 5147 号, 淮坊学院外国语学院(261061) 程辉收 
重视横向比较和对结果的评价。西方“物我二分”和中国人 的“天人合一”的认识论基础及其思维特点不同, 美国大学 入学考试目的只是在于考察考生的思维, 但美国学校注重 开拓精神的培养, 学校会鼓励学生去尝试, 去想象, 而这 种做法恰恰是培养创造性人才不可或缺的要素。在中国, 因为考试只注重结果, 考试成绩决定一切, 导致了学生被 迫陷于题海战术中, 这样恶性循环下去就变成了学生的厌 学情绪泛滥, 进而学习效率及其低下。

\section{2 考试形式、内容和评价}

(1)中美高校入学考试形式比较: 美国高校入学考试可 以分成两个种类, 一种叫做一般能力考试, 一般能力考试 修改后包括三部分: 阅读、数学和写作; 一种叫做专业学业 成就考试, 专业学业成就考试包括英语、数学、社会科学、 自然科学和外语 5 大门。除 SAT 考试之外, ATC 考试是美国 中西部和南部最为流行的考试。有四大部分: 教育考试部分、 中学学习课程及成绩、学生个人档案资料以及 ACT 性趣测 试。中国高考: “ $3+X$ ” “3”是必考的语文、数学和外语; “ $X$ ” 是选考的历史、地理和政治, 或者是物理、化学和生物。 美国高校入学考试的次数是每年 7 次, 学生可以从多次考 试的成绩中选择自己最理想的一次作为升学成绩。

(2)中美高校入学考试内容比较: 美国的专门负责升学 的民间考试机构会根据教材来确定如何测试出学生的知识 和能力水平; 而我国的教育部门是通过高考试题来选拔进 入名校的学生。而这种选拔性考试就会衍生出新的问题, 包括出题人人为出偏题和难题, 学生容易钻牛角尖, 全体 中学生始终在茫茫题海中苦练, 最终容易产生高分低能的 学生。

(3)中美高校入学考试评分比较: 美国大学录取新生的 时候既注重文化知识, 还重视学生的综合素质, 如向申请 的大学提交参加社会活动及工作的证明材料, 事实上, 这 些不容易量化的方面其实对于人才培养和成长发挥着更加 巨大的作用, 更有利于培养出有责任感的高素质人才。在 我国当前, 唯一的依据就是高考分数。

\section{2. 新的考试评价体系的建立与展望}

\section{1 动态、灵活、多元化的考试评价体系}

SAT 考试是美国的一种成功的大学入学考试, 我国的 高考改革既要学习其优秀的内容, 又要注意不能照搬, 不 能脱离中国国情。我们要在学习国外先进的制度的基础上 走出一条适合我国自身发展的道路。

(1)考试标准动态化: 动态化是指考试由原来的结果性 评价慢慢过渡成过程性评价, 由原来的十年磨一剑, 由高
考一考定终身逐步变成将学生的中学日常成绩和社会实践 作为学生入学的重要参考标准, 以期改变考试指挥教学的 现状。改变猜题、押题的现象, 变成社会需要什么就考什 么, 而不是考什么就学什么的现状。考试内容方面, 美国 重视应用和能力, 而中国则偏重理论和知识。只有学以致 用才能很好地激发学习兴趣。以中国的英语考试为例, 因 为英语考试的内容与日常生活严重脱节, 导致了学生离开 学校后不久就将所有的英语相关知识还给了老师, 甚至连 26 个字母都记不起, 更不要说单词和文章了。再比如, 2014 年的山东高考的英语试题取消了听力部分, 于是全国一片 哗然, 毕竟作为语言, 听力、口语、阅读和写作是四项最 基本技能, 如果取消了口语还勉强接受的话, 或者说是不 得不接受 (人员太多, 无法一对一进行测试); 听力的取消 就是最大的语言测试的忌讳了。其实这个取消听力的做法 正是说明了英语的考试内容严重脱离实际这一现状。

(2)考试方式灵活多样: 我国的考试方式主要是笔试, 其它的考试如实验考试、口语考试等等都没有, 这样很难 测试出学生的动手能力、听说能力。我国高考试题主观题 大于客观题; 美国高考客观题大于主观题。在我国因为主 观题被附有严苛的标准答案而将优势大打折扣。美国的客 观题注意做到注重逻辑思维、并且很好得处理了主观题的 结合的关系问题, 因此做到了在批评中生长、发展。

(3)考试评价多元化: 我国高考是很好地做到了标准化, 而这种标准化测试有很大的弊端。其评价只注重知识, 特 别是应试知识。知识也分理论和应用性知识的。英语测试 的听说测试属于应用性测试, 其实英语测试是应当听力、 口语、阅读与写作共同测试的。这种评价方式最能测试出 学生的实际英语水平。如果我们的英语测试卷能够让母语 是英语的人先做做试试, 就能够很好得试出这份试题的评 价意义到底大不大了。如果一味去钻牛角尖, 连母语是英 语的人都不能及格的话, 那么这份试题的信度就不高了。 我们的高考是一年一度, 成绩是唯一评价; 美国的中学成 绩、中学期间的社会实践、自荐信和推荐信等等都有一定 比例的评价比重。我国高考仅有笔试, 美国既有笔试还有 面试等。我国高考仅仅测试认知领域, 美国测试还包括情 感领域和应用能力。我国的高考改革尽量实现纵向的考试 类型, 让学生看到自己的进步, 而不是仅仅横向竞争; 实 现过程性考试, 让学生注意平时表现, 而不仅仅注意最终 结果; 实现全面的考试内容, 让学生除了理论知识的学习, 更要提高能力等综合素质。

\section{2 中美高校入学考试的发展趋势}

(1)制度、政策方面: 高考应由专业化的独立机构(如教 
育测试服务中心) 来承担, 美国高校入学考试的编制实施工 作不是政府, 而是民间机构。目前, 考试机构在我国就是 教育行政机构, 我国高校的管理也是各级政府部门, 这样政 府部门即使考试事务及相关工作的管理部门同时又是监督 部门, 这样既是运动员又是裁判员, 身兼数职的状况必然 不利于推动高考改革。因此, 建立专业型的社会考试机构, 独立性是最重要的, 独立于高校, 更独立于政府之外, 将 目前高考与高校招生一体化操作变为高考与高校招生相对 分离。

(2)内容方面: 基础理论笔试与实践相结合,鼓励体现个 人见解, 包括: 首要任务是要摆脱过于重视知识点的记忆; 其次, 考试内容不能一味地追求理论知识的深度、广度; 再 者, 考试内容要尽可能减少有关道德、价值话语; 考试内容 还要尽可能减少非此即彼的思维模式。我国高考内容转向 注重基础理论的理解、信息的收集及如何处理上来; 注重 理论与实践结合, 做到学以致用, 将学习考核的内容和实 际工作中的需求很好得统一起来。注重批判精神的培养; 注 重创新精神的培养。同时在考试中注意由低到高的多层次 学习与测试, 不同进度、深度和广度的测试能够针对水平 层次不同的学生来进行。不能让水平高的学生觉得无聊, 也不能让水平相对差的学生失去了兴趣和信心。

(3)形式方面: 内容分段考法, 如:语文考试有总分、听 力分、口语分以外, 还有单独的写作分数。增加考试机会, 变高考一考定终身为多种、多次考试机会。

(4)评价方面: 分段考试、分开记分及淡化百分制, 高 考中存在“1 分否决”现象, 如果淡化百分制而以等级制来评 价就会很好地刻意地模糊分数, 避免此类现象的发生。如
果能够将课程分成多阶段, 比如在高中的三年中将考试课 程分高一结业、高二结业和最后一年结业的三个阶段, 就 可以很好地减轻中学生的负担。

综上所述, 以中国与美国高校入学测试对比研究为主 线, 以考试原本设想和意图、实施现状和存在问题以及改 进和应对策略为基本思路，并在中西对比的基础上，达到 提高广大青少年和专业技术人员对于考试的理念、知识和 应对方法与策略的目的。

选取中美高校入学考试为重点, 在青少年和普通民众 中宣传和普及高考的原本的意图和意义, 分析目前考试存 在的问题, 并与美国高校入学考试等进行对比, 剔除我们 在考试和学习方面的不足, 为考试和学习“正名”的同时, 引导人们形成对高校入学考试的科学理念, 使国内高考走 向科学轨道。中国的高考改革还有很长的路, 随着整个社 会的持续性发展和进步，高考改革也必将会越来越深入。

\section{参考文献(References)}

[1] Sen Qi, Study of American Examination, China Examination, 2004.1.

[2] Yingjie Wang, Development and Reform of American Higher Education, Beijing, People's Education Press,1993..

[3] Quanyu Huang, Entrance Examination in America, Beijing, Beijin University Press, 2003.

[4] Nicholas Lemann. The Big Test: The Secret History of American Merrittocracy. 2000.9. 